\title{
Putting pregnancy in its place: Conceiving pregnancy as carework in the workplace
}

\author{
Caroline Gatrell* \\ Lancaster University Management School, Department of Management Learning and Leadership, Lancaster LA1 4YX, UK
}

\section{A R T I C L E I N F O}

Article history:

Received 5 September 2009

Received in revised form

11 November 2009

Accepted 4 December 2009

Available online 16 December 2009

Keywords:

Carework

Health advice

Maternal health

Pregnancy as a 'condition'

Workplace

\begin{abstract}
A B S T R A C T
This paper contributes to understandings of the relationship between pregnancy, health and place by exploring how health advice on pregnancy may be implemented, in practice, 'at work'. The paper first defines the following of health advice on pregnancy as a form of informal 'carework' which obliges pregnant women to implement caring practices comprising emotional and embodied labour. It then observes how health advice on pregnancy carework pays little regard to the impact of place. Drawing upon in-depth interviews with 15 professionally employed mothers/expectant mothers; the paper suggests that the performance of pregnancy carework may be incompatible with workplace settings. The tensions are highlighted between medical representations of pregnancy as a 'condition' and the treatment of pregnancy, within professional workplaces, as 'not an illness'. The question is raised as to whether insufficient reference to place within health advice reflects underlying gendered expectations that pregnancy carework ought to be performed within the home.
\end{abstract}

(c) 2009 Elsevier Ltd. All rights reserved.

\section{Introduction}

It has long been established that pregnancy is medicalized within 'Western' health care settings (as noted by Longhurst, 2001; Nettleton, 2006; Gatrell, 2008). Referring to the medicalization of pregnancy, Woliver (2002, pp. 1-2) has observed how the 'framing of reproductive issues predominantly within a medical and scientific domain draws our attention away from the social ... forces that also impact on [maternal and infant] health'. This paper helps to shift the debate on pregnancy and health from a bio-medical towards a more social domain by showing how the embodied and emotional labour required of pregnant women, according to health advice on pregnancy, may be defined as a form of informal 'carework'. The definition of 'informal carework' used in this paper is drawn from the work of David Morgan (1996), who describes carework as often unpaid, familial and gendered, provided by women who feel under obligation to care for dependent and/or vulnerable family members.

Drawing upon contemporary debates about carework, the maternal body and workplaces, the paper offers an original perspective on pregnancy carework and place within the UK. Although the study is UK based, the relationship between pregnant bodies and the place they occupy has previously been identified by McDowell (1999), Longhurst (2001) and Woliver

\footnotetext{
* Tel.: +44 1524 593924; fax: +44 1524844262

E-mail address: c.gatrell@lancaster.ac.uk
}

(2002) as a research topic of international concern. Similarly, Longhurst, 2001, Woliver, 2002, Young, 2005 and Gatrell, 2008 have each prioritized the medicalization of pregnancy as requiring further investigation. This paper thus develops sociological understandings of the interconnections and tensions between the medicalization of pregnancy and place. In so doing, it addresses important issues in relation to maternal and infant health which have international implications for debates on pregnancy carework, health and the workplace.

The paper first articulates the following of health advice during pregnancy as a form of carework, and then identifies how such health advice makes little reference to place. It goes on to explore how far professionally employed pregnant women are able to implement pregnancy carework in practice, within their workplaces. Finally, the question is raised as to whether health advice on pregnancy might reflect underlying assumptions that pregnancy carework should be carried out within the home.

Specifically, the paper investigates how 15 professionally employed mothers in the UK interpreted and negotiated the boundaries across and between the domains of health advice and their workplaces as they attempted to undertake pregnancy carework 'at work'. The paper observes how mothers appeared to accept medical definitions of pregnancy carework as a maternal 'obligation' which they had a duty to prioritize (a finding also observed in research by Longhurst, 2001 and Brewis and Warren, 2001). Pregnant respondents taking part in this study high lighted the tensions between their sense of pregnancy as a medical 'condition' requiring care, and the definition within their 
workplaces of pregnancy as 'not an illness'. The paper suggests that these tensions impact negatively on maternal and infant health.

\section{Maternity, carework and workplaces}

The choice of pregnancy carework as a site of investigation is in keeping with the recent surge of interest, within health geography, in women's experiences of maternity, carework and place. An increasing number of studies have begun to address women's experiences of breastfeeding within the context of workplace settings, on the basis that place has a direct impact on breastfeeding duration rates, and on maternal and infant health. For example, Galtry (1997), Bailey and Pain (2001), Earle (2002), Mahon-Daly and Andrews (2002), Gatrell (2007), Boswell-Penc and Boyer (2007) and Boyer (2009) all explore infant feeding in the context of paid work. These studies show how the relationship between place and breastfeeding is key because, although the benefits of breastfeeding are well known, many employed women find breastfeeding difficult to maintain, often switching to formula milk when maternity leave ends.

While studies on maternal carework, infant feeding and place are becoming more prevalent, the relationship between pregnancy, health and place has nevertheless been identified by Longhurst (2001), Woliver (2002), Mullin (2005) and Gatrell (2008) as an area which remains under-researched. Additional research is needed on employed women's experiences of pregnancy because health advice on pregnancy does not give sufficient consideration to the importance of place. Health advice, despite the increased numbers of women in the labour market, demands of women particular behaviours and lifestyle changes which might be feasible in the home, but which, as Mullin (2005) observes, may be less easily accommodated by women who are 'at work'. This lack of attention to place is surprising, given that maternal compliance with health advice on pregnancy is deemed important within clinical research in the United Kingdom, the United States and Australia-a factor which is emphasized on pregnancy websites such as NHS Direct (2009a, 2009b), Page (2009) and WebMD (2009). Miles (1992) and Nettleton (2006) discuss how health professionals regard such advice as important because it is based upon medical assumptions that maternal obedience will influence pregnancy outcomes positively, reducing infant death and morbidity and resulting in better health among populations overall.

As a consequence of these assumptions, much emphasis is placed by health professionals, and within the literature written for pregnant women by 'experts', on the need for women to manage pregnancy carework in accordance with medical recommendations. For example, the popular American health advice site WebMD (which is available in the United Kingdom) offers a wealth of guidance on pregnancy, in which it is indicated that women have a duty to 'take steps' to 'ensure a healthy pregnancy' (WebMD, 2009). WebMD frames these maternal obligations via a 'roadmap' of women's 'pregnancy journey'. Mothers-to-be are told of their obligations to begin 'working towards a healthy pregnancy' even before conception, 'learning' and implementing lifestyle 'strategies' to produce a healthy infant. WebMD advises pregnant women that: 'A healthy lifestyle is vital.... Here's what you should (and shouldn't) do'. This statement precedes a wealth of detailed instructions about lifestyle and diet, which women are expected to take on board in order to 'ensure a healthy baby'.

However, while the importance for infant health of such lifestyle changes is underlined and presented to women as a maternal obligation, little attention is given by WebMD to the notion of place, and how place might affect the implementation of pregnancy carework in practice. For example, the advice 'not to get overtired, since rapid growth of the baby can compound the burden on your heart, lungs and kidneys' might be difficult to adhere to within some workplaces.

Given the increasing numbers of women now engaged in different forms of paid employment (as noted by Mahon-Daly and Andrews, 2002), this paper raises questions as to whether, and how, employed pregnant women are managing to negotiate their obligations as both pregnant careworkers and employees. In order to address these questions, and in keeping with MahonDaly and Andrews' (2002) observation that further qualitative research is needed to understand women's experiences of maternity and employment, the current study explores the complexities of managing pregnancy carework 'at work' from the perspectives of 15 professionally employed pregnant women.

\section{Conceiving pregnancy as carework}

The defining, here, of pregnancy as a form of carework builds upon David Morgan's (1996) theoretical delineation of 'informal' (or unpaid) carework as comprising emotional investment, embodied labour and caring practices. These activities are often combined with the added burden of a sense of (often familial) 'obligation' towards the person being cared for. Morgan suggests that the 'obligations' of carework are gendered because women's apparent duty to undertake 'caring practices', especially in relation to children and older relatives, is often taken for granted, and is consequently discounted. Morgan's vision of the close relationship between carework and 'obligation' lends itself particularly well to the concept of pregnancy carework. This is because the notion that pregnant women have an obligation to comply with medical guidelines is central to the ante-natal advice offered to women by midwives and doctors (Young, 2005). The need for maternal compliance is also foregrounded within the 'expert' pregnancy literature (see, for example, NHS Direct, 2009a; WebMD, 2009). This paper observes how employed mothers-to-be may be faced with a double-bind related to place, in that women's obligation to perform pregnancy carework appropriate to their 'condition' is considered inappropriate within some workplaces, where a different kind of bodily objective may be prioritized. The paper then speculates that the very notion of pregnancy carework may be resisted within some workplaces, due to fears that pregnancy brings with it what Cockburn (2002, p. 181) has described as an 'unwelcome whiff of the nursery'.

\subsection{Carework and place}

Having established the relationship between maternal obligation and carework, Morgan (1996) further identifies a link between maternal carework and place. Specifically, Morgan observes how, when informal 'caring practices' are undertaken by women, it is often presumed that the location in which such practices will be undertaken (e.g. caring for an ailing child) is within the home. This is in keeping with McDowell's (1999) observations that parity of caregiving has not been achieved, and that although women's labour market participation has increased, cultural ideas about women's familial, home-based role remain hard to shift. Importantly for the argument in this paper, assumptions that women are responsible for maternal caregiving, and associated beliefs that maternal carework is most appropriately performed in the home, have been shown in research by Cockburn (2002), Boswell-Penc and Boyer (2007) and Gatrell (2008) to cause conflict for employed mothers. Morgan's link between maternal carework and the home brings into question the feasibility of health advice on pregnancy, which makes little 
reference to place. The question is thus raised as to how far women's capacity to implement health advice so as to 'ensure a healthy baby' depends on place. For example, how might professionally employed pregnant women with morning sickness, in workplaces where early starts and long, formal meetings are the 'norm', implement recommendations to take their time getting up in the morning, eat small amounts of food often instead of large meals and sleep whenever possible (NHS Direct, 2009b)? How might such women 'eat healthily to help [their babies] grow' and avoid 'sugary snacks' in workplaces where vending machines supply only crisps and chocolate? How, in their workplaces, might women whose jobs involve desk work and long meetings relieve haemorrhoids by 'not sitting for long periods of time' and/or 'soothing' their discomfort by 'applying an ice pack or witch hazel, [to the affected area] or trying a sitz bath (soaking your bottom in shallow warm water)'(WebMD, 2009)? How might women avoid 'getting tired' at work (NHS Direct, 2009b), and how might they be sure to 'get plenty of rest ... and try taking naps during the day' (WebMD, 2009)?

The above questions suggest that employed women may be faced with conflicting demands if they attempt to follow health advice when they are 'at work'. It is possible to speculate whether - despite the increasing number of women in the labour force health advice might contain underlying inferences that pregnancy carework may most appropriately be performed at home.

\subsection{Pregnancy carework and maternal obligation: on being in a 'condition' at work}

While the theoretical articulation of pregnancy as, specifically, carework is new, the broader social expectation that pregnant women have a duty to embrace health advice on pregnancy has been critiqued within feminist research on women's reproductive health for over three decades by writers such as Oakley (1981, 1984), Katz Rothman (1982), Pollock (1999), Longhurst (2001, 2008), Miller (2005) and Gatrell (2008). These scholars explore the tensions between socio-cultural ideals around women's supposedly 'natural' ability to give birth, and the concurrent expectation that pregnant and birthing women should comply with obstetric guidelines. As Woliver (2002) notes, 'Western' pregnancies are treated as a medical event requiring women to 'nurture' the fetus throughout nine months.

In the context of maternal 'nurturing', Miles (1992), Brewis and Warren (2001) and Gatrell (2010) each observe how the maternal obligation to nurture brings with it assumptions that women should invest time and energy implementing demanding diet and lifestyle changes advocated by medical 'experts'. As a minimum, pregnant women are expected to: follow special diets, abstain from drinking alcohol and smoking cigarettes, monitor their weight, get plenty of rest, take pregnancy-specific exercises and attend regular ante-natal screening appointments. The pregnancy carework involved in following such health advice is laid out on pregnancy websites such as Babyworld (2009), NHS Direct (2009a, 2009b), Page (2009) and WebMD (2009) and is often intricate, requiring women to make lifestyle decisions on the basis of complex information. This complexity applies not only to 'high tech' and potentially risky hospital treatments such as invasive ante-natal screening. Even decisions about everyday issues such as diet require a high level of interpretation. Consider, for example, how mothers might interpret and implement the guidelines offered by 'WebMD' on Vitamin A consumption during pregnancy: 'Choose at least one source of vitamin A every other day. Sources of vitamin A include carrots, pumpkins, sweet potatoes ... Know that excessive vitamin A intake ( $>10,000 \mathrm{IU} /$ day) may be associated with fetal malformations' (WebMD, 2009).
Women's success (or otherwise) in following such advice is monitored closely by the health professionals with whom they interact at ante-natal appointments. This is because pregnant women living in what feminist philosopher Young (2005, p. 47) describes as 'technologically sophisticated Western societies' are expected to accommodate a level of health surveillance usually associated only with serious illness. As Young observes, pregnancy is highly medicalized, and treated 'as a condition that deviates from normal health' (p. 47).

The potential conflict between being in a medical 'condition' while also being 'at work' poses a place-related conundrum for professionally employed women. It is acknowledged how, in the context of the professional occupations in which women who took part in this study are employed (such as academia), some workplaces 'have been coded as disembodied' (Swan, 2005, p. 319). According to Swan (2005) and Hopfl (2000), 'professional' labour is associated with male bodies, which are treated as the norm at work. The description 'disembodied' relates to societal assumptions that 'reliable' men are in control both of their minds and bodies. By contrast, Swan notes, the bodies of professionally employed women tend to be regarded as 'problematic', unpredictable and out of place in professional workplaces, this leading some women to try and hide the 'imagined femaleness inherent in their bodies' (Swan, 2005, p. 319). Similarly McDowell (1997) (while cautioning against generalizations about the workplace) nevertheless observes how, within some professions such as banking, women may be judged as 'fecund and unreliable ... and so unfit for the cool rationality' of some professional workplace settings (McDowell, 1997, p. 34).

\section{Analysing pregnancy carework through Total Social Organisation of Labour (TSOL)}

The idea of being a pregnant body within workplace settings where some women feel obliged to hide their inherent 'femaleness', suggests a need to analyse how women perform pregnancy carework at work. This analysis requires a framework which articulates sociological perspectives on 'work' and 'place' and facilitates a consideration of the pregnant body between the domains of home and work. To achieve this, the paper now draws upon Miriam Glucksmann's: 'Total Social Organisation of Labour' (TSOL; Glucksmann, 1995, 2005). TSOL is the chosen framework because, as Acker (2005) observes, TSOL is designed specifically to conceptualize women's work (paid and unpaid) within different domains and settings. TSOL is especially relevant to studies such as this one, which seek to address the relationship between women's informal carework, their paid work, and place.

Central to Glucksmann's argument is her refusal to create a duality between women's unpaid carework, and the paid work of employment. Glucksmann acknowledges carework as a form of 'work' which may be unremunerated and performed within both the home and the workplace (Glucksmann and Nolan, 2007, p. 97). TSOL has been applied, by Glucksmann and others, to articulate the performance of elder care within both workplaces and the home (Taylor, 2004; Glucksmann and Lyon, 2006, 2008). Similarly, TSOL has been considered in relation to domestic labour (Bradley, 2007) and the mothering of infant children (Gatrell, 2008). However, pregnancy has not previously been articulated as, specifically, a form of 'carework'. This may be because pregnancy is assumed to be a 'natural' part of the performance of 'good motherhood' (Miller, 2005) and has therefore previously been classified as what Glucksmann (2005, p. 19) terms a 'nonwork process'. However, Glucksmann's delineation of carework as open to interpretation across and between places is now brought to bear. Drawing upon both TSOL, and on Morgan's (1996) theory 
of carework as obligation, this paper attempts a conceptualization of pregnancy as a form of carework.

\subsection{Elements of pregnancy carework: emotion work, consumption work, embeddedness and body work}

Glucksmann identifies three elements which are employed here to reflect the obligation and practice of pregnancy carework, namely: consumption work, emotion work and embeddedness (Glucksmann, 2005). For the purposes of this study, Glucksmann's three elements of carework are understood as follows:

- 'Consumption work' is applied to illuminate the work involved in the researching and interpreting of health advice by pregnant women.

- 'Emotion work' defines the emotional energy expended in making decisions about, and implementing, the obligations of pregnancy carework in accordance with health advice.

- The notion of 'embedded' carework acknowledges as 'work' pregnancy-related activities which have often been discounted, due to assumptions that women's maternal caring obligations should come 'naturally' (Miller, 2005).

Emotion work, consumption work and embeddedness are helpful in articulating the carework required of pregnant women. Thus far, however, the body has not been taken into account. For the purposes of this particular paper, this omission could be seen as problematic, and Glucksmann's TSOL is extended here by adding the element 'body work' to the list. The inclusion of 'body work' is important because, as Morgan observes, women's familial and carework practices usually involve 'bodily practices' (Morgan, 1996, p. 113). In relation to pregnancy, for example, the selfregulation required of women with regard to diet requires a particular form of 'body work' (Longhurst, 2001; Warren and Brewis, 2004). It is acknowledged that 'body work' could be interpreted from a wide range of perspectives (Swan, 2005; Wolkowitz, 2006; Gatrell, 2008). However, within this study the body work required of pregnant women is delineated according to Wolkowitz's (2006, p. 146) definition as: the 'work that people are expected to undertake on [their own bodies] in order to meet the expectations of [others]'- here, the adoption of health guidance.

In what follows, consumption work, emotion work, embeddedness (Glucksmann, 2005), and the added concept 'body work' are drawn upon to assist in understanding how women interpret the obligations of pregnancy carework, and how place specifically the workplace - can impact upon the implementation of pregnancy carework.

\section{Data and methods}

This qualitative study builds on a previous, more quantitative study on pregnancy and workplace discrimination (Gatrell, 2010). The present research was instigated because an anonymous reviewer of the previous study recommended further qualitative, attitudinal research on the experiences of employed pregnant women. This reviewer advocated in-depth interviews to reveal the underlying complexities and ambiguities of women's experiences of managing their pregnancies within workplaces. A small grant was applied for to fund the project, and the ethical guidelines of the funding institution were followed.

The data presented below reflect the attitudes towards pregnancy carework among 15 professionally employed women. Like Warren and Brewis (2004, p. 222), who examined 11 women's experiences of being pregnant, the intention in this study was not to 'generalize the findings to other women's experience'. Rather, the intention is to analyse the experiences and attitudes of these 15 women, and to interpret their interview data drawing upon the TSOL (Glucksmann, 2005) and the concept of carework as a form of 'obligation' (Morgan, 1996).

All participants were interviewed in person and interviews were digitally recorded. In some qualitative projects, the average length of time for a qualitative interview may be limited to around $1 \mathrm{~h}$ (Balfe et al., 2009). In this study, given the sensitive nature of the topic, interviews were significantly longer. Most took between 2.5 and $3 \mathrm{~h}$ to complete. With three exceptions, participants were not known to me but were referred through 'snowballing' (as in the qualitative study on 15 pregnant accountants conducted by Haynes, 2008). All but two women had one child or more. Taking into account recommendations by Buzzanell and Liu (2007) to include pregnant women in the sample, three respondents were pregnant at the time of the interview, this enabling a mixture of present experience and what Warren and Brewis (2004, p. 222) refer to as the 'richness of experience ... contained within ourselves structured by memory'. Three women described pregnancies which did not result in a live birth, these examples illustrating the complexities of defining, and understanding, the carework of pregnancy and maternity.

Within the sample, all women were in a relationship at the time of the interview, some women having had children with previous partners. Fourteen women were in heterosexual relationships, one in a lesbian partnership. All were employed in a senior managerial or professional context in the UK. Occupations included: academia, science, finance, health (clinical and managerial), general management, and management consultancy. Thirteen women were white; two self-identified from ethnic minority backgrounds but emphasized their desire to remain anonymous, thus the ethnic background of individual participants is not reported. In keeping with many women in managerial and professional roles, nine mothers had delayed childbearing until their late 30s and early 40s (Dex et al., 1998). Of those who began childbearing earlier, two had more than one child, with second and third children born after age 35 .

The women came from a range of geographical locations within the UK. While most interviews involved travel on my part, some women chose to come to me, one person driving over 200 miles and staying overnight. Some respondents found it challenging to recount their experiences, but remained keen to do so. One woman explained: 'I don't really want to talk about this, but I do want it to be talked about so I want to do the interview.'

In order to protect the identity of participants, specific details are not given regarding the ages, gender and numbers of children/ pregnancies, or the occupation of participants. All names and any identifying details have been changed.

\section{Analysis}

The qualitative interview data comprised in total 706 pages of transcribed material. These were analysed, initially, using the computer software package 'w.matrix', which uses both key words and thematic analysis in relation to physiological and social themes (Rayson, 2008). The data were analysed on two levels. First, the main themes which emerged as prominent within the texts were identified. These themes were then investigated in more detail, using key words and returning to the raw data in terms of listening to recordings and reading transcripts. Among the main themes which arose within the data were: place (women's workplace and their homes); pregnancy as a 'condition' 
and/or 'not an illness'; health advice, diet and lifestyle changes; ante-natal care, anxiety, 'natural' mothering and surveillance.

\section{Observations and discussion}

The medicalization of pregnancy, the notion of pregnancy as a 'condition', and the maternal obligation to take 'steps' to 'ensure a healthy pregnancy' (WebMD, 2009) were strong themes in all interviews. However, women's capacity to follow health advice appeared to be dependent on place, and health advice proved difficult to implement 'at work'. Before going on to discuss the problems of performing pregnancy work in their workplaces, it is important to acknowledge that participants all reported trying to follow health advice in order to 'do everything I can to have a healthy baby'.

Women's attempts to follow health advice could be articulated as carework, in the sense that these efforts all involved women in emotion, consumption and body work, and the practices of obligation (Morgan, 1996). Thus, all women invested emotion and intellect in consuming and interpreting health advice about diet, lifestyle and health during pregnancy. As well as seeking advice from their own midwives and doctors, women turned to 'official' medical and health websites such as WebMD and NHS Direct, as well as to mainstream commercial advice sites such as Babyworld (2009), to the point where they had 'read everything'. University employee Julia recounted how she 'read it all up on the Internet, I did masses of reading on it and I became an expert'.

For all 15 women, adherence to health advice on diet during pregnancy required some form of self-denial. All women gave up (or reduced their intake of) reputedly unhealthy, but commonly consumed food and substances such as alcohol, peanut butter, soft cheese and coffee. Twelve women reported giving up alcohol entirely (a thirteenth did not drink for religious reasons) and the remaining two drank significantly less. Kim, who regularly drank wine when socializing related how she: 'gave up alcohol as soon as I knew ... I just gave up alcohol, I didn't even have a sip of champagne at my friend's birthday'.

All women were aware of expectations that they should change their bodily lifestyles for medical reasons in order to accommodate pregnancy, and all described ways in which they had done this. For example, scientist Beth gave up running even though she found this 'really hard'. Despite 'hating' this, six women stopped using hair dye in response to 'expert' warnings on pregnancy websites such as Babyworld (2009) that dyeing hair could damage the baby. For example, senior academic Claire stopped dyeing her hair after reading that 'hair dye is bad, that it could be bad for the baby'.

Miriam, similarly, recalled how she disliked forgoing her regular bleached highlights but nevertheless reduced her visits to the hairdresser, because she feared that using hair colour might compromise her ability to manage her pregnancy 'responsibly'.

Diet and lifestyle were not the only area where mothers felt obliged to perform carework. All women attended ante-natal screening appointments, women over 35 being required to make decisions about (and to undergo) complex and usually invasive ante-natal tests, within hospital settings. In keeping with Longhurst's (1999) and Davidson's (2001) observations, women were regaled with advice offered not only by health professionals and on pregnancy websites but from friends and partners. Male partners (as in Longhurst's 1999 study) showed particular interest in the technologies of ante-natal care, and sought involvement in decision-making about hospital screening technologies. For example, Amelie reported how her partner discussed with her the pros and cons of amniocentesis and 'thought I should have one', advice which Amelie found difficult to disregard when she decided against this test.

Pregnancy carework also involved elements of embeddedness, in that women committed time and energy to interpreting and following health guidelines, but found this carework to be discounted because it was considered to be a 'natural' maternal obligation (Miller, 2005). For example, senior manager Shelley recounted how her husband thought it should be 'easy' for her to give up wine with her evening meal due to his belief that abstinence should come 'naturally' to pregnant women.

\subsection{Pregnancy in its place: performing carework 'at work'}

Having established that women in the study accepted in principle the value of health advice the paper now examines how the medical concept of pregnancy as a 'condition' was experienced and interpreted by women when within their workplaces. It is important to acknowledge, here, that workplace attitudes towards pregnancy may vary. Longhurst's (2008) research indicates that, within some female-dominated professions such as nursing and teaching, pregnancy may be the focus of positive attention from colleagues-sometimes to the point where supposedly helpful 'support and advice' may become intrusive (2008, p. 35).

By contrast, among the women who took part in this research, however, all recorded feeling under some pressure to downplay their maternal carework obligations when 'at work'. This was because, within their workplace settings, women appeared to feel subject to a different set of obligations which were at odds with the prioritization of pregnancy carework because they required women to 'ignore' pregnancy.

Executive manager Jeanette, who was five months pregnant at the time of her interview, explained her sense that:

I have been given the impression [at work that] if you are pregnant you are required to ignore it; you are required to forget that you are pregnant. This is quite difficult, especially when the baby starts moving, it is quite difficult to just say 'oh none of that matters' because obviously everything changes so vastly and your diet changes and you are physically changing, too and trying to deal with that.

In keeping with Jeanette's observations, all women reported their sense that, when in their workplaces, organizational priorities were expected to override the concept of pregnancy as a 'condition'. Specifically, nine women perceived that pregnancy was regarded as 'not an illness' in their workplaces. When at work, women sensed that they were expected to 'downplay pregnancy' (Costello, 2009). Participants felt under obligation to set aside their duties as maternal careworkers in order to foreground workplace priorities, and also to give the impression that they were intellectually and personally reliable. University employee Grace, for example, described her sense that it was imperative to 'keep pregnancy out of the workplace'.

This notion of pregnancy as 'not an illness' is in total contrast to the medical interpretation of pregnancy as a 'condition' (Young, 2005), obliging mothers to give precedence to the task of nurturing their own pregnant bodies (Miles, 1992; Brewis and Warren, 2001; Longhurst, 2001, 2008; Miller, 2005). Consequently, women felt under pressure to present their bodies, when in their workplaces, as if operating 'normally'. Women's desire to present their pregnant bodies as 'normal' compromised their ability to perform pregnancy carework in accordance with health advice.

Although all participants had expressed their desire to follow health advice as assiduously as possible, eight women reported 
consuming 'unsuitable' food or drink at work due to the embarrassment involved in refusing refreshments which were regarded as commonplace within workplaces. Annabel, a senior health manager, referred to her pregnancy as 'being like, in a condition' which made her 'really anxious about diet'. However, while she believed that 'caffeine might be bad for the baby', Annabel was reluctant to refuse cups of tea and coffee at meetings:

For me pregnancy was a time of terrors ... it was not just the big things but the constant worries about things like food. I was totally paranoid about the diet thing. I was terrified of eating or doing something that might damage the baby. As an NHS manager I had read all this stuff and took in every detail. So ... I stopped eating cheese and peanut butter ... but I found it difficult refusing coffee which we usually drink all the time.

Perhaps more worryingly, and certainly at variance with health guidance, two women related occasions when they continued to work with substances which they believed to be inappropriate. One of these cases involved a public health manager who visited farms and restaurants where problems had been identified with food supplies. This woman dealt with her concerns by refusing food and drink and by washing her hands with a surgical scrub following her visits. The second woman, Elizabeth, was a scientist whose case I now describe in more detail. Elizabeth reported feeling 'highly anxious throughout pregnancy' and this is unsurprising given the circumstances in which she was working. Elizabeth continued while pregnant, to work with chemicals which she knew to be toxic, rather than insist upon the workplace risk assessment which could relieve her of the duties involving chemicals. She explained:

The primary problems I had at work were [because] there are a lot of chemicals. I knew I shouldn't be working with these chemicals so I tried to take control of it but if you have a custom and practice in an environment of working with chemicals ... it is very difficult and I couldn't remove myself from [it].

Elizabeth attempted to compensate for her exposure to chemicals at work by cutting them out of her daily life. She reported:

I didn't want to use anything like nail varnish and similarly deodorant, and I have to say that is right, so I tried not to use deodorant.... I tried to cut down on toxic anything, I didn't even want to go into shops or anything where I thought I could smell things that were toxic.

Nevertheless, when she was 'at work', Elizabeth felt she had little alternative other than to continue working with these chemicals due to her unique expertise in her field:

They wouldn't have had anyone else [to do my job] and there isn't the money to buy in somebody so ... we would have had a legal situation I think if I refused.

Although not all cases were as specific as Elizabeth's there was a sense that most respondents experienced some level of pressure to pursue workplace activities which appeared to contravene health advice. For example, at variance with health advice 'not to get too tired', all but one woman admitted to having 'pushed on' in her workplace on occasions when they felt ill and exhausted. All tried to minimize the impact of pregnancy carework on workplace routines so as to avoid being labelled 'problematic' (Swan, 2005), or unreliable. On the basis that pregnancy was not treated as an 'illness' within their workplaces, and contrary to the medical idea of the pregnant 'condition', women felt obliged, when at work, to distance themselves from any hint that they might be 'ill', or absent through sick leave. University employee Marnie reported being told by her Head of Unit that her pregnancy was 'very inconvenient'. As a result, despite 'very bad back problems', Marnie took trouble with her appearance and ensured she fulfilled all commitments, so she could not be criticized for failing to do her job properly: 'I never missed anything when I was pregnant, I was hyper vigilant around that'.

Like Marnie, other women in the sample perceived the need to present themselves at work primarily in the image of a worker who was 'healthy' and 'reliable'. Maternal obligations to perform pregnancy carework were downplayed by all women, who attempted to keep pregnancy 'in the background'. This aim of downplaying pregnancy was sometimes difficult to achieve, especially if women were fighting nausea, imbalance, or other pregnancy symptoms.

Nevertheless, although two interviewees did have to take some time away from work due to morning sickness, all women did their best to work through this and maintain a presence in their workplaces. Scientist Elizabeth pointed out that it 'had not occurred' to her to take a day off work, through five months of morning sickness. Another woman, university employee Tracy, was sick every day, but continued working throughout. Tracy describes one occasion when, having worked a series of very long hours, she:

felt so faint I ate like two packets of biscuits all in one go because I had been working all day teaching and I was supposed to be [introducing an evening] seminar. [So] I ate all of these biscuits and I felt like I was going to be sick and I ran out and threw up in the car park at work ... But thank goodness I had my car keys [with me], so I could hide it and go straight home and I got cleaned up and then ... well, I went back to work.

Working long days through pregnancy despite feeling sick and exhausted, and eating packets of biscuits to prevent fainting (as opposed to 'healthy snacks') does not accord with the kind of guidance offered in health advice about not getting 'too tired' and eating a healthy diet. The challenge of trying to reconcile, with the idea of being in a medical 'condition', what senior manager Sophie described as the 'workplace mantra' that pregnancy is 'not an illness' caused some women to feel anxious and conflicted.

For example, senior manager Jemima expressed ambivalence regarding the juxtaposition of medical notions of pregnancy as a 'condition' needing care and the view, within her workplace, that pregnancy is 'not an illness'. Jemima found this tension especially confusing given that, during the first six months of pregnancy she felt very unwell:

I think there's this thing around at work that pregnancy is not an illness, it's not even a condition, and I would sort of agree with that. It isn't an illness but it is a very big thing and women react to it in different ways and for me I have to say, the first four to six months I [was sick every day] and I really did feel ill.

\section{Conclusions}

The research highlights the tensions between the idea of pregnancy as a medical 'condition', and the pressure experienced by women in the sample to appear 'as normal' when 'at work'. Health advice on the importance of pregnancy carework does not appear to transfer easily into workplace settings and women in the study felt obliged to 'downplay' pregnancy, even when they were feeling unwell. Women acknowledged that they felt unable to comply, when at work, with health advice on pregnancy 
carework due to their perception that they were supposed to 'ignore' pregnancy within their workplaces.

Reasons why women felt constrained in their attempts to implement pregnancy carework at work are complex. However, the study indicates two factors which may be significant. In the first place, pressures on women to 'ignore' pregnancy and to 'push on' through sickness and exhaustion, may relate to the arguments put forward by Swan (2005) and Hopfl (2000): that certain workplace cultures and occupations privilege what Hopfl (2000) refers to as 'male norms'. The partiality for 'male norms' could be seen as creating problems for these pregnant women, who feel obliged to downplay their 'inherent femaleness' (Swan, 2005, p. 319) by minimizing pregnancy carework in order to fit in with workplace notions of reliability and presence.

Secondly, it is possible to speculate that health advice on pregnancy might also have been difficult to implement within women's workplaces due to underlying assumptions, reflected in health advice, that women's carework is most appropriately performed in the home. It is significant that health guidance on pregnancy carework makes little reference to place, and offers slender guidance on how pregnancy carework might be implemented at work. Common sense suggests that instructions about napping during the day and using ice packs to relieve haemorrhoids would be entirely inappropriate within most workplaces, whatever the occupation of the pregnant woman. It is also perhaps worth noting that, even in the home, compliance with health advice might be difficult especially in situations where there are other children to look after, and where no one else is available or willing to 'do' the 'cleaning and cooking' as recommended by NHS Direct (2009a).

Furthermore, pressure on women to 'ignore' pregnancy and pregnancy advice could relate to unarticulated organizational beliefs (identified by Morgan, 1996 and Cockburn, 2002 in relation to infant carework) that pregnancy carework should be conducted in the home. Significantly, more than one interviewee reported how - especially once pregnancy became visible - she was advised to 'go home', even though this did not reflect her own wishes. Emily, for example, recounted how:

the less politically aware ones were the ones to say the comments that everybody else was thinking like ... Get out of here, go home now, you know. And a lot of people did tell me to go home. Because I didn't want to go home I wanted to stay, you know but I was almost to my due date and people really did start [on me]... and I think behind it all was 'wow, are you sure you should still be here, get out of here, go home'.

It has already been acknowledged that the intention of this study is not to generalize the experiences of Emily and the other 14 women. However, drawing upon the work of Glucksmann (2005) and Morgan (1996) the study has demonstrated how implementing health advice on pregnancy may be seen as a form of carework, both theoretically and in practice. The research has also revealed how the carework required of pregnant women may be strongly influenced by place and, specifically, may be problematic to implement 'at work'.

If we accept the notion that maternal compliance with health advice enhances maternal and infant health, ${ }^{1}$ then the results of this study must be taken seriously. Further research is needed so that bio-medical guidance on pregnancy, and the subsequent health advice offered to pregnant women, acknowledges the

\footnotetext{
${ }^{1}$ For over 30 years now, feminist scholars such as Oakley (1984) and Young (2005) have questioned the benefits of medical and health interventions during pregnancy. Their work suggests the need for further research (both medical and sociological) on how far the following of health and obstetric guidelines can be shown to improve maternal and infant health.
}

social pressures that also influence maternal and infant health. For increasing numbers of employed women, performing pregnancy carework at home may be both impractical and undesirable. Contemporary medical advice therefore needs to recognize the importance of place, and to conceive of how pregnancy carework might be performed 'at work'.

\section{Acknowledgments}

I should like to thank the two anonymous reviewers for their helpful advice on this paper. For comments on an early draft thanks are due to Dr Ellie Hamilton, Dr Valerie Stead and, especially, Dr Elaine Swan. For research support, thank you also to Maureen Cox, Val Goulding, Stuart Riley and Paul Rayson. Finally, I would like to acknowledge Lancaster University Small Grants Committee for funding this project.

\section{References}

Acker, J., 2005. Class Questions, Feminist Answers (Gender Lens series). AltaMira Press, Lanham, MD.

Babyworld, 2009. Is it safe to use hair dye when pregnant? 〈www.babyworld.co. uk $>$

Bailey, C., Pain, R., 2001. Geographies of feeding and access to primary health care. Health and Social Care in the Community 9 (5), 309-317.

Balfe, M., Brugha, R., O'Connell, E., McGee, H., O’Donovan, D., 2009. Where do young Irish women want Chlamydia screening services to be set up? A qualitative study employing Goffman's impression management framework. Health \& Place doi:10.1016/j.healthplace.209.07.003.

Boswell-Penc, M., Boyer, K., 2007. Expressing anxiety? Breastpump use in American wage workplaces. Gender, Place and Culture 14 (5), 51-567.

Boyer, K., 2009. Of care and commodities: breast milk and the new politics of mobile biosubstances. Progress in Human Geography, 1-16, doi:10.1177| 0309132509105003.

Bradley, H., 2007. In: Gender. Polity Press, Cambridge.

Brewis, J., Warren, S., 2001. Pregnancy as project: organising reproduction. Administrative Theory and Praxis 23, 383-406.

Buzzanell, P., Liu, M., 2007. It's 'give and take': maternity leave as a conflict management process. Human Relations 60, 463-495.

Cockburn, C., 2002. Resisting equal opportunities: the issue of maternity. In: Jackson, S., Scott, S. (Eds.), Gender: A Sociological Reader. Routledge, London, pp. 180-191.

Costello, M., 2009. The added bump in the economy for pregnant women. Thursday May 7, 10:36pm EDT, Reuters, www.reuters.com.

Davidson, J., 2001. Pregnant pauses: agoraphobic embodiment and the limits of (im)pregnability. Gender, Place and Culture 1, 283-297.

Dex, S., Joshi, H., Macran, S., McCulloch, A., 1998. Women's employment transitions around childbearing. Oxford Bulletin of Economics and Statistics $60,79$.

Earle, S., 2002. Factors affecting the initiation of breastfeeding: implications for breastfeeding promotion. Health Promotion International 17 (3), 205-214.

Galtry, J., 1997. Suckling and silence in the USA: the costs and benefits of breastfeeding. Feminist Economics 3, 1-24.

Gatrell, C., 2007. Secrets and lies: breastfeeding and professional paid work. Social Science \& Medicine 65, 393-404.

Gatrell, C., 2008. In: Embodying Women's Work. Open University Press, Maidenhead.

Gatrell, C., 2010. Policy and the pregnant body at work: strategies of silence, secrecy and supra-performance. Gender Work and Organization, doi:10.1111/ j.1468-0432.2009.00485.

Glucksmann, M., 1995. Why 'work? Gender and the 'Total Social Organization of Labour'. Gender, Work and Organization 2, 63-75.

Glucksmann, M., 2005. Shifting boundaries and interconnections: extending the 'total social organisation of labour. Sociological Review 53 (Suppl.), 19-36.

Glucksmann, M., Lyon, D., 2006. Configurations of care work: paid and unpaid elder care in Italy and the Netherlands. Sociological Research Online 11, $\langle$ http://www.socresonline.org.uk/11/2/glucksmann.html $\rangle$.

Glucksmann, M., Lyon, D., 2008. Comparative configurations of carework across Europe. Sociology 42, 101-118.

Glucksmann, M., Nolan, J., 2007. New technologies and the transformation of women's labour at home and work. Equal Opportunities International 26 96-112.

Haynes, K., 2008. Transforming identities: accounting professionals and the transition to motherhood. Critical Perspectives on Accounting 19, 620-642.

Hopfl, H., 2000. The suffering mother and the miserable son: organizing women and organizing women's writing. Gender, Work and Organization 17, 98-105. 
Katz Rothman, B., 1982. In: In Labor: Women, and Power in the Workplace. W.W. Norton, New York.

Longhurst, R., 1999. Pregnant bodies, public scrutiny: 'giving' advice to pregnant women. In: Teather, E.K. (Ed.), Embodied Geographies: Spaces, Bodies and Rites of Passage. Sage, London, pp. 78-90.

Longhurst, R., 2001. In: Bodies: Exploring Fluid Boundaries. Routledge, London.

Longhurst, R., 2008. Maternities: Gender, Bodies and Space. Routledge, New York.

Mahon-Daly, P., Andrews, G., 2002. Liminality and breastfeeding: women negotiating space and two bodies. Health and Place 8, 61-76.

McDowell, L., 1997. Capital Culture, Gender at Work in the City. Blackwell, Oxford.

McDowell, L., 1999. In: Gender, Identity and Place, Understanding Feminist Geographies. Polity, Cambridge.

Miles, A., 1992. Women, Health and Medicine. Open University Press, Buckingham.

Miller, T., 2005. In: Making Sense of Motherhood: A Narrative Approach. Cambridge University Press, Cambridge.

Morgan, D., 1996. In: Family Connections: An Introduction to Family Studies. Polity, Cambridge.

Mullin, A., 2005. Reconceiving Pregnancy and Childcare: Ethic, Experience and Reproductive Labour. Cambridge University Press, New York.

Nettleton, S., 2006. In: The Sociology of Health and Illness second ed. Polity Press, Cambridge.

NHS Direct, 2009a. NHS choices; your health, your choices. Pregnancy and childbirth: what foods should I avoid during pregnancy, 〈www.nhsdirect.nhs. uk>, accessed 30.08.09.
NHS Direct, 2009b. The pregnancy care planner: stay healthy at work, www.nhs.uk/ Planners/pregnancycareplanner/pages/Healthatwork.aspx, accessed 21.10.09.

Oakley, A., 1981. In: From Here to Maternity: Becoming a Mother. Pelican Books, Harmondsworth.

Oakley, A., 1984. In: The Captured Womb. Blackwell, Oxford.

Page, S., 2009. The principles of ante-natal care. Women's Health Aus <http:// www.medicineau.net.au/clinical/womenshealth/Antenatal.html\#anchor4 $\rangle$.

Pollock, D., 1999. In: Telling Bodies: Performing Birth. Columbia University Press New York.

Rayson, P., 2008. From key words to key semantic domains. International Journal of Corpus Linguistics 13, 519-549.

Swan, E., 2005. On bodies, rhinestones and pleasures: women teaching managers. Management Learning 36, 317-333.

Taylor, R.F., 2004. Extending conceptual boundaries: work, voluntary work and employment. Work, Employment and Society 18, 29-49.

Warren, S., Brewis, J., 2004. Matter over mind? Examining the experience of pregnancy. Sociology 38, 219-236.

WebMD, 2009. Health and Pregnancy, 〈www.webmd.com/baby/guide/healthpregnancy-just-the-facts $\rangle$, accessed 21.08 .09

Woliver, L., 2002. In: The Political Geographies of Pregnancy. University of Illinois, Chicago.

Wolkowitz, C., 2006. In: Bodies at Work. Sage, London.

Young, I.M., 2005. In: On Female Body Experience: 'Throwing Like a Girl' and Other Essays. Oxford University Press, Oxford. 